Scientific Paper

\title{
Dosimetry audit of the CyberKnife accelerator with the SHANE phantom
}

\author{
Marcin SZYMAŃSKIa,", Maria PIZIORSKAa, Oskar MADETKOa, Wioletta ŚLUSARCZYK-KACPRZYK ${ }^{\text {, }}$ \\ Wojciech BULSKI ${ }^{\mathrm{b}}$ \\ ${ }^{a}$ Masovian Oncology Hospital, Wieliszew, Poland \\ ${ }^{b}$ Maria Skłodowska-Curie National Research Instiute of Oncology, Warsaw, Poland \\ *E-mail address: szymanski.marcin@live.com
}

\begin{abstract}
Introduction: The aim of this study was to propose a dosimetric audit of the CyberKnife system. Dosimetry audit is an important part of the quality assurance process in radiotherapy. Most of the proposed dosimetric audits are dedicated to classical medical accelerators. Currently, there is no commonly implemented scheme for conducting a dosimetric audit of the CyberKnife accelerator.

Material and methods: To verify the dosimetric and geometric parameters of the entire radiotherapy process, as is required in E2E test procedure, the CIRS SHANE anthropomorphic phantom was used. A tomography with a resolution of 1.5 mm was prepared, five PTVs (Planning Target Volume) of different volumes were drawn; approximately: $88 \mathrm{~cm}^{3}, 44 \mathrm{~cm}^{3}$, $15 \mathrm{~cm}^{3}, 7 \mathrm{~cm}^{3}, 1.5 \mathrm{~cm}^{3}$. Five treatment plans were made using the 6D Skull tracking method, FIXED collimators, RayTracing algorithm. Each treatment plan was verified in a slab Phantom, with a PinPoint chamber. The dose was measured by an ionization chamber type TM31010 Semiflex, placed in the center area of the target.

Results: The result of the QA verification in slab phantom was up to 5,0\%. The percentage difference for the measurement in the SHANE phantom was: $4.29 \%,-1.42 \%,-0.70 \%, 1.37 \%,-1.88 \%$ respectively for the targets: $88 \mathrm{~cm}^{3}, 44 \mathrm{~cm}^{3}, 15 \mathrm{~cm}^{3}$, $7 \mathrm{~cm}^{3}, 1.5 \mathrm{~cm}^{3}$.

Conclusions: By analyzing various approaches to small-field dosimetry audits in the literature, it can be assumed that the proposed CyberKnife dosimetric audit using the SHANE phantom is an appropriate method of verification of the radiotherapy process. Particular attention should be paid to the target volume, adjusting it to the system capabilities.
\end{abstract}

Key words: CyberKnife; audit; dosimetry; SHANE; quality assurance.

\section{Introduction}

For many years now, the International Atomic Energy Agency (IAEA) and the World Health Organization (WHO) carry out activities aiming at increasing the quality and effectiveness of radiotherapy and at ensuring standardization of dosimetric procedures worldwide. This applies in particular to the low-andmiddle-income countries (LMIC). ${ }^{1}$ The IAEA has organised a number of Coordinated Research Projects (CPR) in order to ensure a high level of the methodologies and of the beam quality control procedures used in radiotherapy. As an example of such programs, one may cite the IAEA/WHO postal dose audit service, or a more comprehensive project, the QUATRO (Quality Improvement Quality Assurance Team for Radiation Oncology). Poland takes an active part in quality assurance programmes of this kind, implementing the IAEA/WHO recommendations concerning quality assurance.,

Polish legislation requires adequate programmes of the control of radiation doses in radiotherapy to be implemented at each radiotherapy facility. The Polish Atomic Law of 29 November 2000 (revised 13 June 2019) defines a clinical audit as: systematic control or revision of medical radiological procedures aiming at the improvement of the quality of medical services provided to patients. ${ }^{4}$ The audits may be internal or external. The regulation of the Minister of Health of 3 April 2017 divides the external audit into two parts - the audit of the medical procedures and the dosimetry audit. Dosimetry audits are carried out using the methods which are able to detect $5 \%$ or smaller dose differences in the controlled beams. Each radiotherapy centre has to be externally audited once a year., 5 The dosimetry audit has to be performed either by a laboratory recognized by the IAEA, or by other laboratories possessing appropriate accreditation.

In Poland, since 1991, the dosimetry audits are performed by the Secondary Standard Dosimetry Laboratory which is part of the Medical Physics Department of the Memorial Maria Skłodowska-Curie National Institute of Oncology in Warsaw.

At present, the majority of the dosimetry audit methods are designed to test conventional medical accelerators. In the literature, there are very few proposals of how to carry out a dosimetry audit for CyberKnife or Tomotherapy systems. There is no commonly accepted scheme of how to perform such an audit. In this study, following the recommendations of the IAEA on dosimetric audits, the possibility of adopting a SHANE 
phantom to perform a CyberKnife system audit was investigated. The IAEA audit recommendations for the IMRT/VMAT technique is composed of many elements such as MLC positioning accuracy, MLC shaped small field profile measurement, 2D dose distribution measurement using dosimetric film and point dose measurements with an ionization chamber in the anthropomorphic phantom. ${ }^{7}$ The main focus is placed on the ionization chamber measurement, since this method can be easily adapted to a high fraction dose which is commonly prescribed for treatment using the CyberKnife system. The ionization chamber measurement can be used for a consistency check of one site, and to compare the results obtained in different sites.

The construction and functioning of a CyberKnife device make it difficult to apply conventional methods of dosimetry audits. Characteristics of stereotactic techniques (Stereotactic Body Radiotherapy, SBRT) and of radiosurgery (Stereotactic Radiosurgery, SRS) such as delivering a high dose in one or several fractions, or the presence of very high dose gradients, or the use of very small fields, require minimalization of the possibility of committing a dosimetry error and thus underline the need of a well-defined procedure for the dosimetry audit. In stereotactic radiotherapy, a limitation of the use of the technique is the too large size of the lesion.,.$^{\mathbf{9}}$

\section{Material and methods}

\section{CyberKnife}

Irradiation was carried out on CyberKnife VSI equipped with fixed collimators and IRIS Variable Aperture Collimator, RoboCouch System. One of the main components of the CyberKnife System (Figure 1) is a linear accelerator mounted on a robotic arm that performs any movement rotating independently around six axes. A table which is a part of the patient positioning system called RoboCouch, uses a robot to move the patient in 6 degrees of freedom. The treatment couch can move in 3 translation directions (Inferior/Superior, Left/Right, Anterior/Posterior) and 3 rotation directions (Roll, Pitch, Yaw). ${ }^{10,11}$ These movement properties enable the irradiation of the patient from many directions (Figure 2). This makes it possible to deliver a very high dose to the target volume sparing the surrounding healthy tissues. ${ }^{11}$

In order to assure patient safety and reproducibility of the treatment, the system verifies patient positioning during irradiation. The system is able to track the position of the target and correct the position with the 6D RoboCouch. In case the target localization is affected by respiratory movements, not only the position of the patient is controlled, but so is the tracking of the target in the respiratory cycle (Synchrony). The positioning errors can be corrected and the respiratory movements can be compensated for by the radiation head movements following the specified respiratory model. In case of discrepancies larger than tolerance limits, irradiation is terminated.

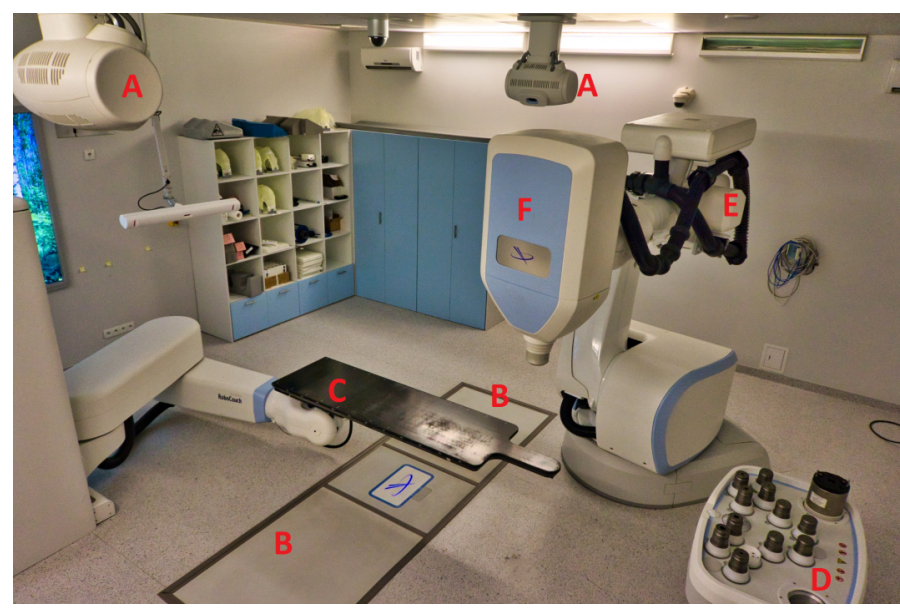

Figure 1. Main components of the CyberKnife system: X-ray Sources of Target Locating System (A), X-ray Image Detectors (B), RoboCouch (C), Xchange Robotic Colimator Changer (D), Treatment Manipulator (E), Linear Accelerator in X-ray Head (F)

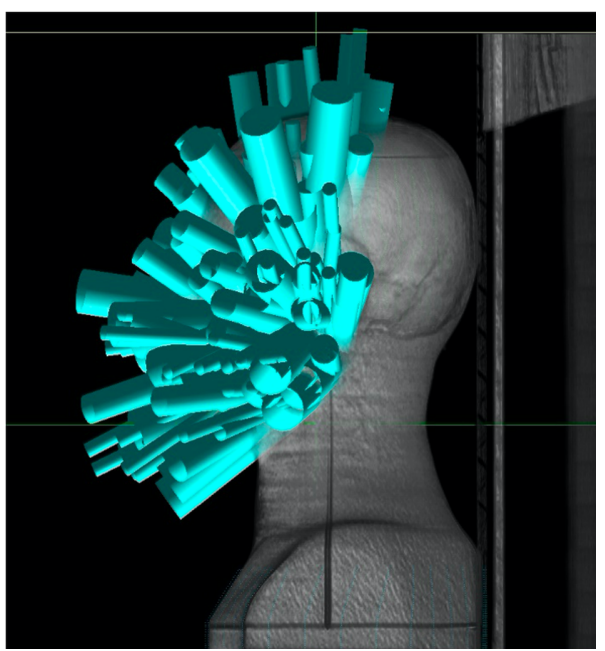

Figure 2. Ilustration of the CyberKnife System treatment beam geometry for the head treatment plan in sagital view

The system of control of the target position is composed of two $\mathrm{X}$-ray tubes mounted in the ceiling and two panels of detectors mounted in the floor (Figure 1). The respiratory movements are tracked by three diodes and a camera hanging over the treatment couch. The data registered by the camera is processed by the dedicated software provided by the manufacturer.,10,11

Treatment plans were prepared using MultiPlan v 4.6.1 treatment planning system (TPS).

\section{SHANE Phantom}

These highly specialized irradiation techniques require adequate quality assurance procedures at the planning stage and during treatment. This proposition of an audit is based on SHANE phantom, in this case it was shared by the IAEA with the Polish SSDL to offer an end-to-end audit for hospitals willing to participate. The anthropomorphic phantom SHANE manufactured by CIRS is designed for comprehensive quality control of the radiotherapy process (Figure 3). 


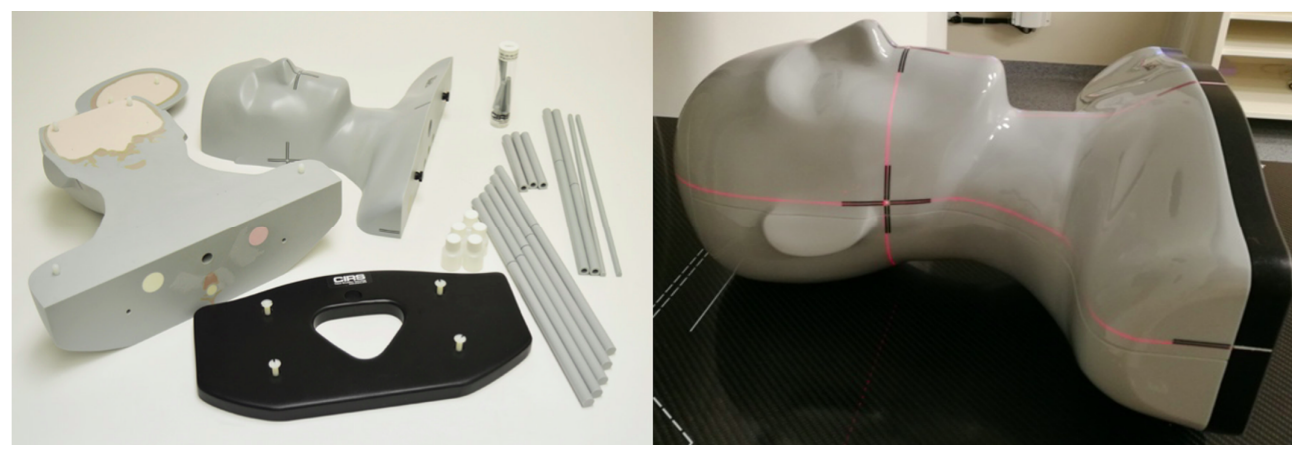

Figure 3. The anthropomorphic CIRS SHANE phantom: SHANE components (left) and assembled SHANE (right)

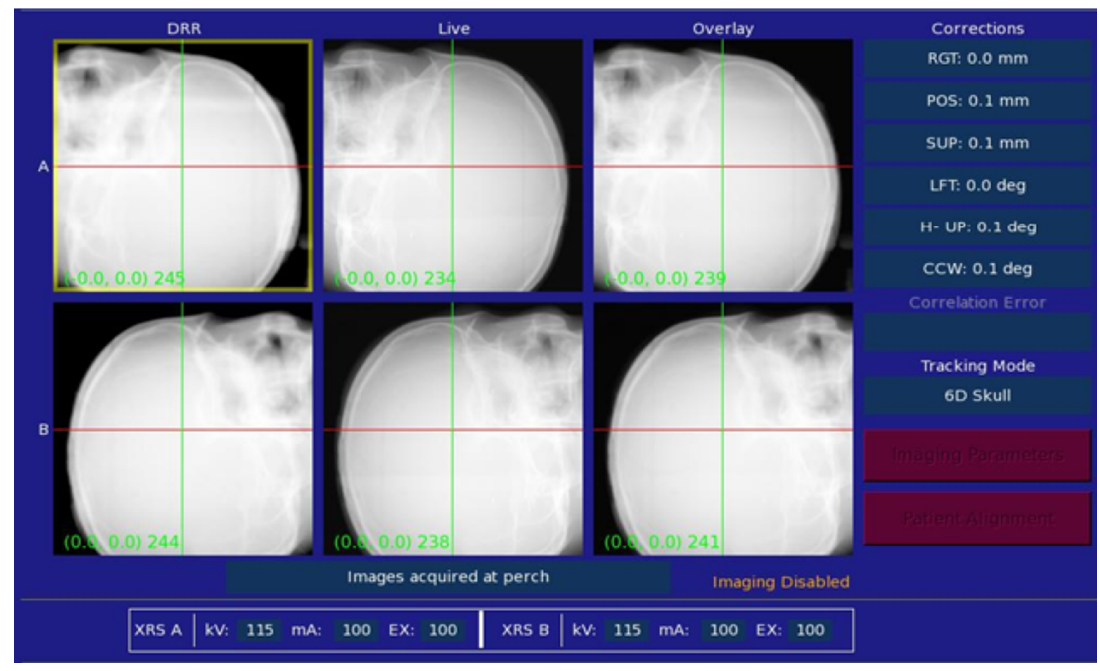

Figure 4. Alignment and Tracking window with acquired X-ray images: a pair of DRR images, a pair of live X-ray images (corresponding to camera $A$ and $B$ of the X-ray imaging system), and a pair of overlying DRR and live images

It contains bone and teeth structures and air cavities typical for the head and neck region. There are four channels for inserting the ionization chamber. The external markers on the phantom surface facilitate accurate and unambiguous positioning. The construction of the phantom makes it possible to place dosimetric films in coronal plane. ${ }^{\mathbf{1 2}}$ The bony structure of the phantom may be used by the positioning system of the CyberKnife.

\section{Dosimetric equipment}

This proposition of an audit is based on the IAEA end-to-end on site audit methodology employing SHANE phantom (CIRS). The output was measured by a PTW Farmer ionization chamber and a PTW Unidos Webline electrometer. QA verification measurement was performed with a PTW RW3 slab phantom with permanent fixed markers and a set of PTW PinPoint 3D TM31016, $0.016 \mathrm{~cm}^{3}$ volume chamber with a PTW Unidos Webline electrometer. Both measurement sets have valid calibration certificates from the Polish SSDL. A thermometer and a barometer were also calibrated. A semiflex chamber was adopted to check the dose in the SHANE phantom after crosscalibration with a Farmer chamber used for output measurements. ${ }^{13}$

\section{CT imaging}

In order to follow the principles of the end-to-end audit, CT imaging of the phantom was performed according to the clinical protocol for CyberKnife, at our department. The scans was collected with $1.5 \mathrm{~mm}$ slice thickness. CT acquisition was performed on a Siemens AS Definition unit, with solid rod inserts. The SHANE Phantom, provided by the IAEA was configured for use just with a Semiflex ion chamber.

In the treatment planning system, a fusion of the IAEA scans and of local scans was performed. Thus the structures provided at the IAEA scans for the audit of conventional accelerators were transferred to the locally performed scans. Using local CT scan enables to verify the correct definition of the local CT unit within the TPS. ${ }^{7}$

\section{Align (positioning verification)}

In order to verify the SHANE phantom positioning, a 6D Skull method was used (Figure 4). It allows for the tracking of alterations of intracranial lesions on the basis of the anatomy of the skull. ${ }^{11}$ The system uses gradients of brightness in order to compare the DDR images generated and the x-ray images registered. Patient alignment and alteration tracking is possible without using invasive stereotactic frames. ${ }^{14}$ 


\section{Preparation of the target volume}

The target volumes proposed and provided by the IAEA for the audit with the SHANE phantom are designed for conventional accelerators. In order to test the usefulness of the SHANE phantom for stereotactic radiotherapy, a $88 \mathrm{~cm}^{3}$ IAEA target was used, and four smaller targets prepared locally. The treatment plans were prepared for the following lesion sizes: $88 \mathrm{~cm}^{3}, 44$ $\mathrm{cm}^{3}, 15 \mathrm{~cm}^{3}, 7 \mathrm{~cm}^{3}, 1.5 \mathrm{~cm}^{3}$ (approximately).

\section{Treatment plans}

The main goal was to prepare a treatment plan that is typical for the centre audited.

End-to-End IAEA audit guidelines recommend the creation of a clinically acceptable IMRT or VMAT treatment plan. The plans were prepared for three different targets, with different prescribed doses $(70,60,54 \mathrm{~Gy})$ to be delivered in 30 fractions. The IAEA recommends constraints for target volumes and organs at risk. ${ }^{7}$ For the CyberKnife system audit, a single fraction SRS technique was used, a prescribed dose of $20 \mathrm{~Gy}$ at the $80 \%$ isodose encompassing the singular target. Encompassment of at least $98 \%$ of the PTV volume by the prescribed isodose was achieved. The number and the shape of the collimators depended on the target shape, two or three FIXED type collimators were used. The conformality Index for the PTV structure did not exceed 1.5.

Not all structure contours supplied with the SHANE phantom used in the IAEA audit are applicable for the CyberKnife technique. ${ }^{7}$ This is due to the presence of high dose gradients. In order to adjust the anatomical structures for the CyberKnife audit, the following structures provided with the phantom were used: irradiation region: PTV_7000 (renamed as PTV_20Gy), organ at risk: BrainSteam, Parotid_L, Parotid_R, SpinalCord. Due to the geometry of the beams used on the CyberKnife, the following additional structures were drawn: Eye_L, Eye_R, OpticNerve_L, OpticNerve_R, Chiasm, MedullaOblongata, Brain, Skin. For dosimetric purposes only, the contours of the ionization chambers provided by the IAEA were used: IC_PTV. All clinical CyberKnife procedures should be met. Any plan prepared should pass the local quality assurance protocol.

The technical parameters of the prepared plans are presented in Table 1. For the dose distribution calculation, the RayTracing algorithm was used. ${ }^{11}$ All structures, with the exception of the PTV and of the IC_PTV, were treated as critical areas and the dose was kept as low as possible..$^{15,16}$ Dose distribution images for the plans prepared are presented in Figure 5.

\section{Dosimetric preparation}

The ionisation chamber dose measurements were taken in accordance with the recommendations of the IAEA report TRS 483. ${ }^{17}$ Corrections for small fields were taken into account. The output of the accelerator was controlled under reference conditions ${ }^{\mathbf{1 7}}$, before starting the QA verification and taking the phantom measurements. The output deviation to the reference values did not exceed $0.5 \%$.

\section{QA verification}

Each treatment plan was verified in a slab phantom with the ionization chamber and an electrometer. ${ }^{18}$ Routinely, the ionization chamber is placed in the volume of the target where the dose gradient is the lowest, then it is encompassed by the highest possible isodose. In order to assure the reproducibility of the verification conditions used in this research project, the contour of the chamber (IC_PTV) was centred on the PinPoint chamber delineation in the slab phantom. Subsequently, the dose from the treatment plan was recalculated for the CT of the slab phantom. The slab phantom was placed on the treatment couch and positioned accurately by use of the patient position control system. The irradiation planned was performed and the dose was measured.

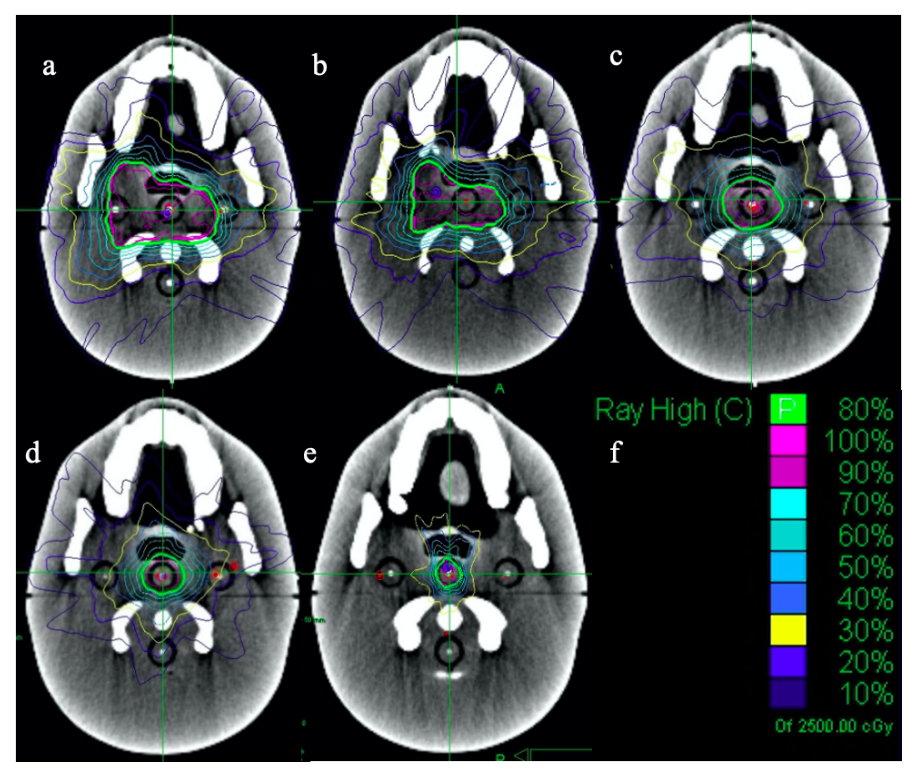

Figure 5. Dose distributions in treatment plans for 5 target volumes: (a) $88 \mathrm{ccm}$, (b) $44 \mathrm{ccm},(\mathrm{c}) 15 \mathrm{ccm},(\mathrm{d}) 7.5 \mathrm{ccm},(\mathrm{e}) 1.5 \mathrm{ccm}$, (f) scale

Table 1. Technical parameters of the treatment plans

\begin{tabular}{|c|c|c|c|c|c|c|c|c|}
\hline $\begin{array}{l}\text { PTV volume } \\
\text { [ccm] }\end{array}$ & $\begin{array}{c}\text { Collimator size } \\
{[\mathrm{mm}]}\end{array}$ & $\begin{array}{c}\text { Collimator } \\
\text { type }\end{array}$ & $\begin{array}{l}\text { Number } \\
\text { of beams }\end{array}$ & $\begin{array}{l}\text { Number } \\
\text { of nodes }\end{array}$ & $\begin{array}{l}\text { Number } \\
\text { of MU }\end{array}$ & $\begin{array}{l}\text { Time } \\
{[\mathrm{min}]}\end{array}$ & $\begin{array}{c}\text { Conformality index } \\
\text { of PTV }\end{array}$ & $\begin{array}{c}\text { PTV coverage } \\
{[\%]}\end{array}$ \\
\hline 88.055 & $10,20,30$ & Fixed & 230 & 90 & 3219.74 & 68 & 1.15 & 99.98 \\
\hline 43.875 & $7.5,15,25$ & Fixed & 141 & 74 & 25814.21 & 57 & 1.15 & 99.36 \\
\hline 15.139 & $7.5,15,25$ & Fixed & 95 & 46 & 7955.56 & 27 & 1.12 & 99.63 \\
\hline 6.830 & $5,12.5,20$ & Fixed & 79 & 44 & 7696.72 & 25 & 1.10 & 99.37 \\
\hline 1.502 & $5,12.5$ & Fixed & 39 & 28 & 13637.18 & 27 & 1.31 & 98.86 \\
\hline
\end{tabular}


Table 2. Results of measurements in SHANE phantom and in a slab phantom

\begin{tabular}{ccccc}
\hline \hline $\begin{array}{c}\text { PTV volume } \\
{[\mathbf{c c m}]}\end{array}$ & $\begin{array}{c}\text { TPS SHANE } \\
\text { mean dose IC [cGy] }\end{array}$ & $\begin{array}{c}\text { SHANE } \\
\text { measured dose [cGy] }\end{array}$ & $\begin{array}{c}\text { TPS-SHANE } \\
\text { phantom difference [\%] }\end{array}$ & $\begin{array}{c}\text { TPS-slab } \\
\text { phantom difference [\%] }\end{array}$ \\
\hline 88.055 & 2278.34 & 2376.12 & 4.29 & 2.41 \\
43.875 & 2335.17 & 2302.10 & -1.42 & 3.77 \\
15.139 & 2363.27 & 2346.67 & -0.70 & 1.09 \\
6.830 & 2428.77 & 2462.07 & 1.37 & 2.34 \\
1.502 & 2346.78 & 2302.77 & -1.88 & 0.63 \\
\hline \hline
\end{tabular}

The dose measured in the slab phantom was referred to as the mean dose determined by the treatment planning system, in the PinPoint ionization chamber contour, in the verification plan.

\section{Realization of the treatment plan}

After QA measurements of five plans, the measurements in the SHANE phantom were performed. Due to the very good stability of the position of the phantom, there was no need for verification of patient position during irradiation. The realization time of the plan ranged from 25 to 68 minutes (Table 1). The measurements were performed with ionization chamber type TM31010 Semiflex $0.125 \mathrm{~cm}^{3}$ and a PTW Unidos Webline electrometer. Before each measurement, the temperature in the phantom and air pressure in the treatment room were measured.

\section{Results}

The results of QA measurements in the slab phantom are presented in the fifth column of Table 2. The maximum percentage difference between the dose measured in the slab phantom and that calculated in the TPS was $3.77 \%$.

The results for each plan measured in the SHANE phantom are presented in Table 2. The second column shows the dose calculated in the TPS for the volume of the ionization chamber (IC_PTV). The next column presents the values measured. The mean dose calculated by the TPS was compared with the dose measured in the SHANE phantom. The percentage ratios of comparison are shown in the fourth column.

\section{Discussion}

According to local QA verification protocols, maximum acceptable dose difference does not exceed 5\%. As shown in Table 2, each plan fulfilled this criterion.

The maximum percentage difference between the dose measured in the SHANE phantom and that calculated by the treatment planning system was $4.29 \%$. When analysing methods for dosimetric audits for advanced radiotherapy techniques, Marlies Pasler et al. ${ }^{\mathbf{1 9}}$ evaluated tolerance limits in the range from $3 \%$ to $5 \%$ for the measurements with an ionizing chamber. Therefore, it seems that the proposed method of dosimetric audit of the CyberKnife system using the SHANE phantom is adequate.

The largest percentage difference between the computed and measured dose values was observed for a target volume of 88 $\mathrm{cm}^{3}$. This target was designed (by the IAEA) for the audits of the IMRT technique with conventional accelerators. In all other cases, this percentage difference was below $2 \%$.

The obtained differences between the measured and the calculated doses, mainly for the largest target volume, may be the result of the occurence of many factors, e.g. inhomogenity in the ionization chamber area, inaccurate delineation of the ionization chamber. As was shown in Figure 6, the space contoured as the volume of the ionization chamber is located in the area in which the dose distribution generated by the treatment planning system (TPS) is not homogenous. This fact, together with the inaccuracy of chamber size evaluation (IC_PTV contour), may be the reason for a difference between the dose measured and the mean dose generated by the TPS. The error does not proliferate directly between the consecutive planes because of the varying dose distributions in these planes. Inaccurate contouring of the IC_PTV may generate a systematic error in case of the CyberKnife technique. This is related to high dose gradients in small volumes. In case of the standard techniques (IMRT, VMAT), for which the SHANE phantom was designed, this is not of considerable consequence.

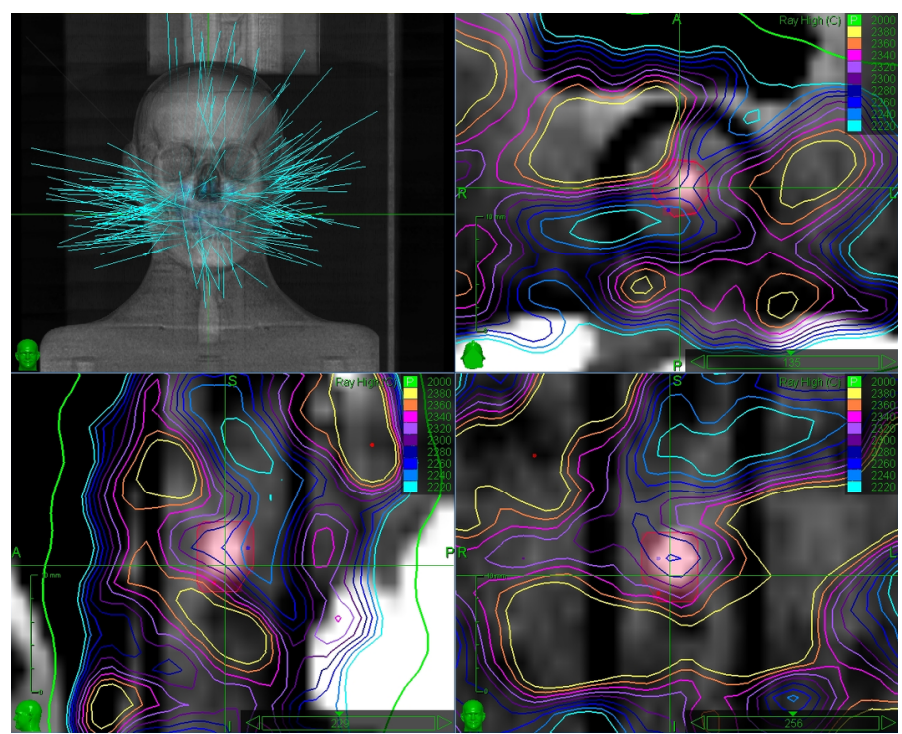

Figure 6. Ilustration of the CyberKnife treatment beam geometry and distribution of isodoses (ranging $2220 \mathrm{cGy}-2380 \mathrm{cGy}$ ) around the area of the ionization chamber in the treatment plan in axial, coronal, and sagital views, for the $88 \mathrm{~cm}$ target volume. Ionization chamber contour is shown in purple. 


\section{Conclusions}

On the basis of the presented results in the high dose region, we conclude that the SHANE phantom may be used for a dosimetric audit of CyberKnife systems. Further investigation is required as far as the dosimetric audit of doses in critical organs is concerned. In this case, it is possible to place the ionization chamber in the small dose region, where a small difference between the measured and the calculated dose, may result in a high percentage difference.
The methodology of the audit prepared by the IAEA requires revising and adaptation for the CyberKnife systems. The prime requirement is the adaptation of the target volumes typical for stereotactic techniques.

Another possible modification is reconfiguration of the SHANE phantom to use with the ionization chamber with a smaller active volume, for example PinPoint. The use of a smaller volume ionization chamber is commonly accepted for small field dosimetry.

\section{References}

1. Konstanty E. International Atomic Energy Agency clinical audits - the way to safe and effective radiotherapy. Zeszyty Naukowe WCO, Letters in Oncology Science. 2018;15(3):83-87.

2. International Atomic Energy Agency, Quality Assurance Team for Radiation Oncology, eds. Comprehensive Audits of Radiotherapy Practices: A Tool for Quality Improvement. International Atomic Energy Agency; 2007.

3. Dosimetry audit networks (Dan) database. Accessed March 22, 2021. https://dosimetry-auditnetworks.iaea.org/home/postaldoseauditservice

4. Obwieszczenie Marszałka Sejmu Rzeczypospolitej Polskiej z dnia 11 września 2019 r. w sprawie ogłoszenia jednolitego tekstu ustawy - Prawo atomowe. Accessed March 22, 2021. http://isap.sejm.gov.pl/isap.nsf/DocDetails.xsp?id=WDU20190001792

5. Obwieszczenie Ministra Zdrowia z dnia 3 kwietnia 2017 r. w sprawie ogłoszenia jednolitego tekstu rozporządzenia Ministra Zdrowia w sprawie warunków bezpiecznego stosowania promieniowania jonizującego dla wszystkich rodzajów ekspozycji medycznej. Accessed May 19, 2021. https://isap.sejm.gov.pl/isap.nsf/DocDetails.xsp?id=WDU20170000884

6. Obwieszczenie Ministra Zdrowia z dnia 22 grudnia 2014 r. w sprawie ogłoszenia wykazu wzorcowych procedur radiologicznych z zakresu radioterapii onkologicznej. Accessed March 22, 2021. http://dziennikmz.mz.gov.pl/legalact/2014/81

7. Clark C, Gershkevitsh E, Lechner W, et al. IAEA Supported National "End-to-End" Audit Programme for Dose Delivery Using Intensity-Modulated Radiation Therapy through On-Site Visits to Radiation Therapy Institutions. Published online 2019. https://dosimetry-audit-networks.iaea.org/Content/end-to-end\%20CIRS\%20SHANE/National\%20end-to-end\%20IMRTVMAT\%20audit\%20methodology.pdf

8. $\quad$ Malicki J, Ślosarek K. Planowanie Leczenia i Dozymetria w Radioterapii (Tom 2). Via Medica; 2018.

9. Inoue HK, Seto K, Nozaki A, et al. Three-fraction CyberKnife radiotherapy for brain metastases in critical areas: referring to the risk evaluating radiation necrosis and the surrounding brain volumes circumscribed with a single dose equivalence of 14 Gy (V14). Journal of Radiation Research. 2013;54(4):727-735. https://doi.org/10.1093/jrr/rrt006

10. Wocial P. CyberKnife S7-Radioterapia najwyższej precyzji. Inżynier i Fizyk Medyczny. 1/2021:10-11.

11. Ding C, Saw CB, Timmerman RD. Cyberknife stereotactic radiosurgery and radiation therapy treatment planning system. Medical Dosimetry. 2018;43(2):129-140. https://doi.org/10.1016/j.meddos.2018.02.006

12. Phantom Patient for VMAT \& IMRT: Data Sheet - CIRS. http://www.cirsinc.com/wp-content/uploads/2020/08/1365-DS-081420.pdf

13. International Atomic Energy Agency, ed. Absorbed Dose Determination in External Beam Radiotherapy: An International Code of Practice for Dosimetry Based on Standards of Absorbed Dose to Water. International Atomic Energy Agency; 2001.

14. Accuray Incorporated. Equipment Specifications. Accessed March 22, 2021. http://www.cyberknifelatin.com/pdf/brochure-tecnico.pdf

15. Grimm J, LaCouture T, Croce R, et al. Dose tolerance limits and dose volume histogram evaluation for stereotactic body radiotherapy. Journal of Applied Clinical Medical Physics. 2011;12(2):267-292. https://doi.org/10.1120/jacmp.v12i2.3368

16. Benedict SH, Yenice KM, Followill D, et al. Stereotactic body radiation therapy: The report of AAPM Task Group 101: Stereotactic body radiation therapy: The report of TG101. Med Phys. 2010;37(8):4078-4101. https://doi.org/10.1118/1.3438081

17. Dosimetry of Small Static Fields Used in External Beam Radiotherapy. INTERNATIONAL ATOMIC ENERGY AGENCY; 2017. https://www.iaea.org/publications/11075/dosimetry-of-small-static-fields-used-in-external-beam-radiotherapy

18. Koksal C, Akbas U, Donmez Kesen N, et al. Patient-specific quality assurance for intracranial cases in robotic radiosurgery system. $\mathrm{J}$ BUON. 2018;23(1):179-184.

19. Pasler M, Hernandez V, Jornet N, Clark C. H., Novel Methodologies for Dosimetry Audits: Adapting to Advanced Radiotherapy Techniques. Physics and Imaging in Radiation Oncology. 2018;5:76-84. https://doi.org/10.1016/j.phro.2018.03.002 